\title{
Sustainable Engineering and Internet of Things (IoT): trends and perspectives
}

\author{
Andrés García-Pérez, $\mathrm{MSc}^{1}$ and Jaime A. Mesa, $\mathrm{PhD}^{2}$ \\ ${ }^{1}$ Universidad Tecnológica de Bolívar, Faculty of Engineering, Department of Industrial Engineering. Cartagena de Indias, \\ Colombia, agarcia@utb.edu.co \\ ${ }^{2}$ Universidad Tecnológica de Bolívar, Faculty of Engineering, Department of Mechanical Engineering. Cartagena de Indias, \\ Colombia,jmesa@utb.edu.co
}

\begin{abstract}
Internet of Things - IoT appeared in the forecast of engineering three decades ago. Since then, a vast range of applications has been developed in industrial, urban, and rural matters, where one of the most relevant issues has been sustainability. This paper presents a retrospective analysis of the most relevant trends in sustainability regarding IoT and its applications, considering evolution trends and tangible results from the last decade (2011-2020). When the concept of sustainability in engineering gained importance. The study provides useful insights into the future development of IoT in human life and industrial activities as well as research opportunities in terms of sustainability based on IoT approaches.
\end{abstract}

Keywords- IoT, sustainability, engineering, smart cities, smart systems.

\section{INTRODUCTION}

Every day more and more objects such as sensors, actuators, appliances, wireless grids, and automated devices are connected to the internet [1]. Such objects are commonly used to measure, diagnose, control, and optimize resource consumption and in the decision-making process towards costeffectiveness. Approaches in engineering cover a wide variety of applications such as transportation, health care, surveillance, smart environments, among others [2].

During the last decade, sustainability has become a capstone topic related to IoT, demonstrating a rapid increase in research interest since 2012 and reaching a remarkable number of articles in less than a decade (see Figure 1).

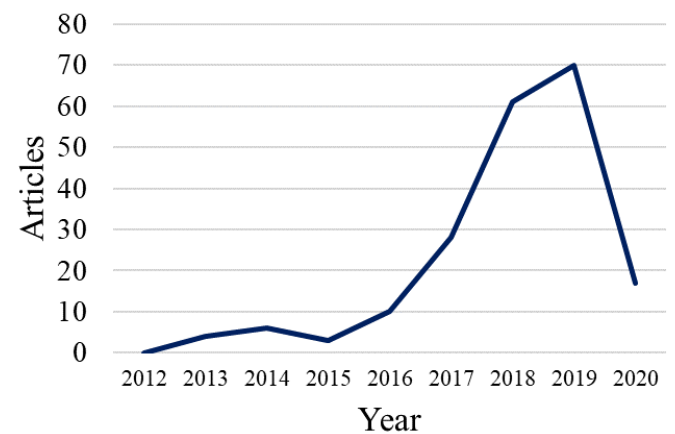

Fig. 1

tion of IoT + Sustainability in peer-reviewed articles. Results from the SCOPUS database.

Sustainable development goals also push the need for more initiatives focused on rapid mitigation of climate change, resource depletion, and pollution, and IoT is a key

Digital Object Identifier (DOI):

http://dx.doi.org/10.18687/LACCEI2020.1.1.109

ISBN: 978-958-52071-4-1 ISSN: 2414-6390 technological enabler to achieve such objective [3]. Besides, the pervasive nature of IoT enables the rapid propagation of sustainability initiatives in the future[4].In terms of IoT and Sustainability, research efforts are concentrated in monitoring, managing, and optimizing resources to enhance the quality of life of people and increase the cost-effectiveness of companies. Tangible results in issues as quality, production costs, resource efficiency demonstrate the vast potential of IoT.

Existing literature reviews regarding IoT are commonly oriented to one field in particular. For example, IoT applied to the sustainability of energy systems [5]; farming or agricultural applications [6]; Social IoT and its services [7]; Internet of medical things [8], [9] and IoT in food safety [10]. Such orientation to particular topics restricts the possibility of viewing the overall picture in terms of all successful implementations of IoT.

Therefore, this article seeks to provide an overview of all IoT applications in the field of sustainable development. Such applications include the enhancement of services and datamanagement in the decision-making of daily activities, saving material consumption, emissions, time, and money. Also, this article analyzes future challenges from selected references in the most important topics or application fields, enabling a holistic perspective of IoT practitioners and academics for future developments and approaches.

The rest of the article is organized as follows. Section II presents the literature review methodology. Section III corresponds to the results of implementing the review methodology. Findings and discussion are included in Section IV. And Future Challenges and Conclusions are described in Sections V and VI, respectively.

\section{LITERATURE REVIEW METHODOLOGY}

The proposed method to analyze the existing literature in IoT and sustainability issues consists of four main steps: i) Information gathering from a recognized database, in this case, SCOPUS. ii) A screening process to discard non-related works based on reviewing title, abstract, and keywords. iii) A detailed reviewing of filtered works. And iv) the analysis of selected works to obtain useful information and data related to trends and challenges in IoT and sustainability approaches.

Figure 2 shows the graphical description of the methodology. Sections III and IV show the results, findings and discussion after performing the methodology. 
Outputs
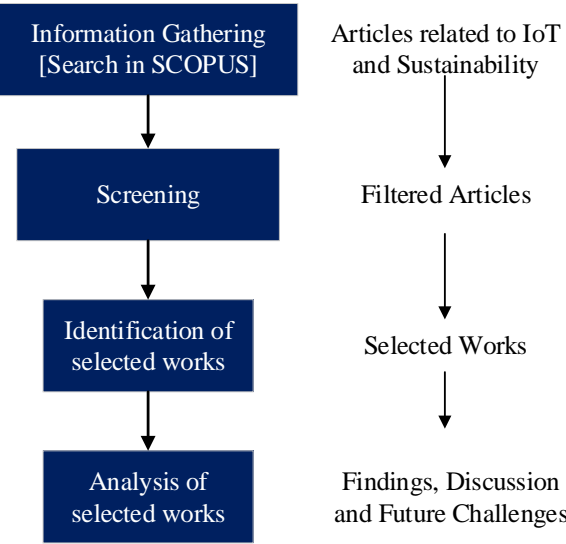

Filtered Articles

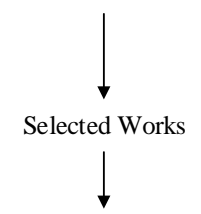

Findings, Discussion and Future Challenges

Fig. 2 Graphical description of literature review methodology

\section{RESULTS}

During the implementation of the literature review process, more than 200 articles were collected and analyzed in the screening process. The gathering of information just included journal articles in the English language. The literature search was performed using "IoT" and "Sustainability" as search keywords. 36 articles were selected after the screening process and identification of selected works. Such works corresponded to sustainable engineering applications with demonstrated results in practice.

Figure 3 summarizes the engineering applications of IoT found in the literature analysis. The most frequent implementation of IoT for Sustainability are smart cities with eleven works, the second most frequent is Circular Economy present in ten works, and the third is Agriculture with nine studies. These three categories demonstrate the interesting issues in which IoT is gaining relevance to improve the efficiency in the use of resources and reducing emissions or waste. In general, the main purpose of Smart Cities applications is to reduce pollutants in the air and improve energy consumption. In the case of Circular Economy is to generate valorization opportunities from material flow and waste, reducing environmental impacts and providing economic benefits. In terms of Agriculture, efforts are addressed towards the best use of water and improve the supply chain management.

\section{A. Identification of research clusters}

Seven main categories were identified from selected works obtained in the literature search. Table I summarizes a sample of representative references and a brief description of each category. Categories were built from the number of works dedicated to the same topic, which is a preliminary

measure of the relative research importance. Individual contributions were not included in Table I.

Categories are comprised of two main topics in order to consolidate the use of IoT for improving resources in a specific application field.

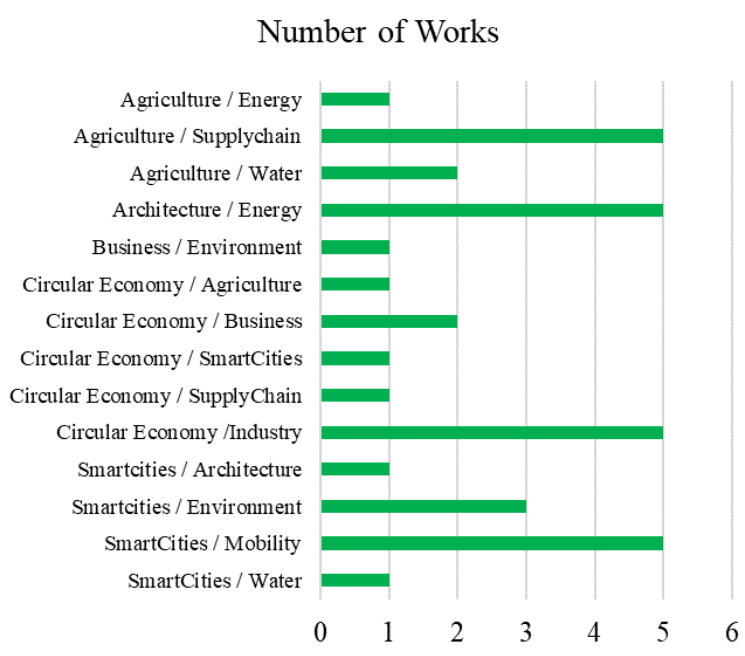

Fig. 3 Applications of IoT in sustainable engineering from the literature review

\section{B. Key indicators per category}

In addition to the information summarized in Table I, an inventory of key indicators is performed and consolidated in Table II. Key indicators consist of engineering parameters that are measured, monitored and optimized through the IoT application for each category

TABLE I. Seven most relevant clusters regarding IoT and Sustainability

\begin{tabular}{|c|c|c|}
\hline Category & $\begin{array}{c}\text { Selected } \\
\text { References }\end{array}$ & Description \\
\hline $\begin{array}{l}\text { Smart Cities } \\
\text { /Energy }\end{array}$ & $\begin{array}{l}{[5],[11]-} \\
{[14]}\end{array}$ & $\begin{array}{l}\text { Monitoring and optimization of energy } \\
\text { consumption towards cost-efficiency in } \\
\text { cities and communities. This topic } \\
\text { includes the implementation of sensors } \\
\text { and the use of previous records to } \\
\text { predict consumption requirements. }\end{array}$ \\
\hline $\begin{array}{l}\text { Smart Cities / } \\
\text { Mobility }\end{array}$ & {$[15]-[19]$} & $\begin{array}{l}\text { Optimization of mobility in urban } \\
\text { environments. Includes efficiency in } \\
\text { times and resources, collaborative } \\
\text { transportation, cycling, among others. }\end{array}$ \\
\hline $\begin{array}{l}\text { Smart Cities / } \\
\text { Environment }\end{array}$ & {$[20],[21]$} & $\begin{array}{l}\text { Includes measurement and treatment of } \\
\text { data for environmental parameters (e.g., } \\
\text { pollutants related to the quality of air) }\end{array}$ \\
\hline $\begin{array}{l}\text { Architecture / } \\
\text { Energy }\end{array}$ & {$[22]-[26]$} & $\begin{array}{l}\text { Studies the monitoring and optimization } \\
\text { of energy consumption in buildings } \\
\text { from the perspective of architecture. }\end{array}$ \\
\hline $\begin{array}{l}\text { Agriculture / } \\
\text { Supply chain }\end{array}$ & {$[27]-[31]$} & $\begin{array}{l}\text { Reduction of waste from production } \\
\text { activities and secondary processes } \\
\text { involved in the whole supply chain of }\end{array}$ \\
\hline
\end{tabular}

Digital Object Identifier: (only for full papers, inserted by LACCEI).

ISSN, ISBN: (to be inserted by LACCEI).

$18^{\text {th }}$ LACCEI International Multi-Conference for Engineering, Education, and Technology: "Engineering, Integration, and Alliances for a Sustainable Development" "Hemispheric Cooperation for Competitiveness and Prosperity on a Knowledge-Based Economy", 29-31 July 2020, Buenos Aires, Argentina. 


\begin{tabular}{|c|c|c|}
\hline Category & $\begin{array}{c}\text { Selected } \\
\text { References }\end{array}$ & Description \\
\hline & & agricultural products. \\
\hline $\begin{array}{l}\text { Agriculture / } \\
\text { Water }\end{array}$ & {$[32],[33]$} & $\begin{array}{l}\text { Use of IoT for measuring and } \\
\text { optimizing water irrigation in } \\
\text { agricultural crop processes. It also } \\
\text { includes the development of water } \\
\text { management applications. }\end{array}$ \\
\hline $\begin{array}{l}\text { Circular } \\
\text { Economy/ } \\
\text { various }\end{array}$ & {$[34]-[40]$} & $\begin{array}{l}\text { Applications approaches and case } \\
\text { studies focused on circular economy } \\
\text { strategies such as reuse, } \\
\text { remanufacturing, refurbishment, and } \\
\text { recycling. Most approaches are oriented } \\
\text { to facilitate and promote the recycling of } \\
\text { products. }\end{array}$ \\
\hline
\end{tabular}

TABLE II. Key indicators for each category. Measurements

\begin{tabular}{|c|c|}
\hline Category & $\begin{array}{l}\text { Key indicators - } \\
\text { Parameters }\end{array}$ \\
\hline Smart Cities /Energy & $\begin{array}{ll}\text { - } & \text { Energy consumption } \\
\text { - } & \text { Cost savings }\end{array}$ \\
\hline Smart Cities / Mobility & $\begin{array}{l}\text { - Transportation Time } \\
\text { - Emissions }\end{array}$ \\
\hline Smart Cities / Environment & $\begin{array}{ll}\text { - } & \text { Pollutants in air } \\
\text { - } & \text { Pollutants in water } \\
\text { - } & \text { Emissions } \\
\text { - } & \text { Temperature } \\
\text { - } & \text { Solar radiation }\end{array}$ \\
\hline Architecture / Energy & $\begin{array}{l}\text { - Energy consumption } \\
\text { - } \quad \text { Costs }\end{array}$ \\
\hline Agriculture / Supply chain & $\begin{array}{l}\text { - Waste from crop } \\
\text { - Costs }\end{array}$ \\
\hline Agriculture / Water & $\begin{array}{ll}\text { - } & \text { Water consumption } \\
\text { - } & \text { Humidity } \\
\text { - } & \text { Costs }\end{array}$ \\
\hline Circular Economy & $\begin{array}{ll}\text { - } & \text { Recycled material } \\
\text { - } & \text { Life Cycle Cost } \\
\text { - } & \text { Global Warming } \\
\text { - } & \text { CPU Consumption } \\
\text { - } & \text { Emissions, Waste } \\
\end{array}$ \\
\hline
\end{tabular}

\section{FINDINGS AND DISCUSSION}

\section{A. Main trends}

IoT has been gaining more and more relevance as the internet and communication technology thrive. During the last decade, the number of connected devices and objects in the world increased rapidly, enabling the massification of applications not only in daily activities but also in industrial environments.

Four main trends can be established from the literature analysis: a) Energy: In terms of research is the most studied and developed field in terms of integration of IoT. This issue covers not only the industrial sector but also smart cities and architecture (smart buildings and houses). The use of sensors and wireless networks has driven the spread of applications, and the growth of renewable sources has also enabled a suitable environment for new business models and consumer behaviour practices.

b) Water: Most improved in the industrial and agricultural fields. Which involves huge consumptions of water during processing, handling, and irrigation activities.

The spread of precision agriculture has also promoted the continuous improvement of irrigation activities. On the other hand, sensors, automated re-circulation systems, and zerowater consumption practices have increased the impact on water consumption as well as in its contamination potential.

c) Environment: Includes the_measurement of parameters such as temperature, pollution in the air, pollution in water, solar radiation, among others. Applications related to this issue are mostly oriented to decision-making activities for industrial and daily activities. Smart cities have included IoT applications to record environmental parameters that can be used to predict weather conditions, adjust energy consumption rates, and perform outdoor activities.

d) Materials (Circular Economy): This last trend has gained relevance, especially during the last four years. As a broad concept, the circular economy promotes the use of materials in a circular fashion path; through closing the loop tasks such as recycling, reuse, remanufacturing, and slowing the loop strategies such as extended life of products, repairability, improved durability among others. For such initiatives, IoT provides digital platforms to enable collaborative circularity of products and information management to facilitate interactions user-user and manufacturer-user.

\section{B. Circular Economy and IoT}

In terms of sustainability, the circular economy concept is considered as a new production model that reduces the extraction of resources and seeks to keep the value of products and materials the long as possible.

IoT applications are key enablers of Circular Economy, providing robust platforms for topics such as:

- Reverse supply chains (manufacturers-usermanufacturers): integrating information about final disposal alternatives, waste management and potential business opportunities from repair products and recycling raw material. IoT enables communication between consumers and manufacturers to stablish supply chains 
based on material flows once the first useful life of products is completed.

- Consumer behaviour - user experience (persuasive design): through IoT applications it is possible to measure and analyse user experience in terms of perception, the average useful life and overall performance of products before purchase a new version for millions of users. In addition, IoT can be used to promote persuasive campaigns to raise awareness of environmental impacts when products are disposed.

- Cloud manufacturing (collaborative manufacturing): IoT facilitates the integration of multidisciplinary teams into the product development process. Manufacture can be improved to reduce emissions, processing time and material and energy consumption. Cloud manufacturing also enables the use of advanced tools (simulations, virtual prototypes) to predict future impacts in use and final disposal stages.

- Digital markets - Secondary Markets (Platforms): customers are aware that secondary markets are a good alternative to find functional products at a lower price. This culture promotes the reuse, and users are already purchasing and offering products in many platforms such as Amazon, ebay, mercadolibre (LATAM), however, this kind of initiatives can be extended to components, spare parts, defective parts among others.

\section{Drivers and Barriers in IoT for Circular Economy}

Drivers for circular economy from IoT applications vary from single users to big companies. Regarding single users, it is possible to mention the growing trend of more environmentally conscious consumers and service users, which is essential to adopt more circular behaviours massively.

In terms of big companies, the use of IoT enables more confident and rapid information and data management. As a result of the accelerated evolution of wireless networks, companies augur more business opportunities from circular economy such as reverse supply chains, cheaper raw material acquisition, increase of environmental added value, and as a marketing differentiator for more environmentally-conscious consumers. The massification of wireless networks around the world also implies a bigger coverage area to obtain more consumer data since interconnectivity is necessary to build circular ecosystems in cities and industrial complexes.

Barriers against IoT for the circular economy include the lack of formal legislation initiatives to promote the massification of IoT applications, which slows the potential impact in terms of savings and resource optimization in industrial and daily activities. On the other hand, some developing countries still do not have full internet network coverage, especially in rural areas (due to armed conflict, difficult access roads, corruption, among others).

As a challenging barrier, it is also possible to mention the absence of formal and hidden curriculum education in high school and college students regarding the circular economy. The concept is relatively new (no more than 15 years), and several countries have not a clear idea about its benefits in terms of economic, environmental, and social aspects.

\section{PERSPECTIVES AND FUTURE CHALLENGES}

Perspectives and challenges of IoT and sustainability are described considering the main sectors of application fields. Each field is described in detail below:

In the agricultural sector, there are limitations to the adoption of IoT applications. Most of the extensive farmers lack formal education, hindering the adoption of IoT for improving productivity, and enable potential businesses. One of the most promissory applications in agricultural activities is the use of fully automated irrigation systems, which are still under-development due to the absence of integration processes with Big Data and heterogeneous sensors.

In terms of buildings construction, IoT provides a considerable variety of improvement opportunities. Including energy savings for refrigeration, heating, and lighting. However, in the case of public facilities, users are not interested or motivated to reduce energy consumption. One of the most common reasons is the lack of information and persuasiveness regarding consumer behavior and its environmental impacts from the perspective of public organizations. Meanwhile, efforts need to be oriented to handle, predict, and visualize data for influencing users towards energy-saving tasks.

One of the most prominent approaches to consider cleaner production consists of monitoring sustainability indicators during the manufacturing stage of products, measuring material flow in the production process, as well as energy consumption and emissions. This kind of application will contribute to rapid decision-making to optimize operations and saving resources and time.

Regarding the Smart cities' topic, some approaches have been proposed to facilitate mobility and reduce emissions. The use of bicycles for mobility is one of the most well-received initiatives, not only reducing the environmental impact but also vehicular congestion and promoting physical exercise in the population. On the other hand, IoT also offers a huge opportunity to collect information about the mobility of people into the city, common routes, timing, among others. With this information, it is possible to predict and program more precise public and private transportation services; to provide optimum routes for users and generate jobs for thousands of people. 
Relevant data could include the condition of highways and streets, traffic restrictions, and available parking lots.

In terms of energy management, IoT has demonstrated enormous potential. Which is focused not only on measuring offer and demand of energy for industries and residential applications but also for predicting future consumptions based on consumer behavior and environmental conditions. One of the most challenging issues in this field is the adoption of machine learning approaches to analyze user behavior on a massive scale (considering millions of energy-based devices simultaneously) to capture consumer patterns and optimize energy consumption in real-time.

In addition to the previously mentioned challenges, some issues are transversal to all fields:

- Platform creation: it is necessary to design and develop monitoring systems to include heterogeneous sensors with different information modeling. Such platforms must be able to process data from diverse IoT sources (e.g., quantitative data about air pollution and qualitative perceptions about traffic status from vehicles)

- Data visualization: implementation of and contextualization of captured data. IoT enables the data recording; however, the visualization of data can be enhanced through graphical representations to improve their full comprehension.

- Policies: governments should establish regulations to promote the generation, processing, and exchange of data obtained from IoT sources, considering the security and privacy of people.

Concerning the massive implementation of IoT, it is necessary to develop diagnostic studies about connectivity and highly potential economic sectors (e.g. tourism and agriculture). Specially in developing countries, which can leverage their economic development through IoT solutions. Rapid diagnostics combined with effective policies/legislations can embrance the appropriation and evolution of IoT as a key tool to fight poverty and inequality in the world.

\section{CONCLUSIONS}

This article studied the main trends and research opportunities regarding the use of IoT for engineering solutions-oriented to sustainability during the last two decades. The analysis of the literature showed that IoT approaches had permeated engineering solutions, providing a robust platform to perform daily and industrial activities efficiently.

Energy and water consumption, emissions, and material flow have been studied massively, enabling sustainability from daily to daily users and industrial actors. As an interesting finding, the concept of the circular economy is gaining attention for implementing IoT solutions. Supply chain, resource management, and reduction of emissions and energy consumption have been considered in the last five years. Thus, IoT can be cataloged as a key enabler for a circular economy in both common daily activities and industrial processes.

Future works regarding IoT for sustainability include the development of robust platforms to optimize data analysis and the data visualization based on information context to facilitate interpretation for any user.

Regarding policies, it is urgent to advance in new regulations to protect sensitive information from users and ensure correct data use for communities' welfare.

\section{REFERENCES}

[1] F. Alkhabbas, R. Spalazzese, and P. Davidsson, "Characterizing Internet of Things Systems through Taxonomies: A Systematic Mapping Study," Internet of Things, vol. 7, p. 100084, 2019, doi: 10.1016/j.iot.2019.100084.

D. Miorandi, S. Sicari, F. De Pellegrini, and I. Chlamtac, "Internet of things: Vision, applications and research challenges," Ad Hoc Networks, vol. 10, no. 7, pp. 1497-1516, 2012, doi: 10.1016/j.adhoc.2012.02.016.

[3] M. Maksimovic, "Greening the Future: Green Internet of Things (GIoT) as a Key Technological Enabler of Sustainable Development," in Internet of Things and Big Data Analytics Toward NextGeneration Intelligence, Cham: Springer, 2017, pp. 283-331.

[4] S. K. Routray and K. P. Sharmila, "Green initiatives in IoT," Proc. 3rd IEEE Int. Conf. Adv. Electr. Electron. Information, Commun. Bio-Informatics, AEEICB 2017, pp. 454-457, 2017, doi: 10.1109/AEEICB.2017.7972353.

[5] P. K. Khatua, V. K. Ramachandaramurthy, P. Kasinathan, J. Y. Yong, J. Pasupuleti, and A. Rajagopalan, "Application and assessment of internet of things toward the sustainability of energy systems: Challenges and issues," Sustain. Cities Soc., vol. 53, no. November 2019, p. 101957, 2020, doi: 10.1016/j.scs.2019.101957.

[6] A. Villa-Henriksen, G. T. C. Edwards, L. A. Pesonen, O. Green, and C. A. G. Sørensen, "Internet of Things in arable farming: Implementation, applications, challenges and potential," Biosyst. Eng., vol. 191, pp. 60-84, 2020, doi: 10.1016/j.biosystemseng.2019.12.013.

[7] M. S. Roopa, S. Pattar, R. Buyya, K. R. Venugopal, S. S. Iyengar, and L. M. Patnaik, "Social Internet of Things (SIoT): Foundations, thrust areas, systematic review and future directions," Comput. Commun., vol. 139, no. September 2018, pp. 32-57, 2019, doi: 10.1016/j.comcom.2019.03.009.

[8] C. Kotronis et al., "Evaluating Internet of Medical Things (IoMT)Based Systems from a Human-Centric Perspective," Internet of Things, vol. 8, p. 100125, 2019, doi: 10.1016/j.iot.2019.100125.

[9] F. Al-Turjman, M. H. Nawaz, and U. D. Ulusar, "Intelligence in the Internet of Medical Things era: A systematic review of current and future trends," Comput. Commun., vol. 150, no. October 2019, pp. 644-660, 2020, doi: 10.1016/j.comcom.2019.12.030. 
[10] Y. Bouzembrak, M. Klüche, A. Gavai, and H. J. P. Marvin, "Internet of Things in food safety: Literature review and a bibliometric analysis," Trends Food Sci. Technol., vol. 94, no. April, pp. 54-64, 2019, doi: 10.1016/j.tifs.2019.11.002.

[11] R. P. Meenaakshi Sundhari and K. Jaikumar, "IoT assisted Hierarchical Computation Strategic Making (HCSM) and Dynamic Stochastic Optimization Technique (DSOT) for energy optimization in wireless sensor networks for smart city monitoring," Comput. Commun., vol. 150, no. November 2019, pp. 226-234, 2020, doi: 10.1016/j.comcom.2019.11.032.

[12] González de-la-Rosa and Pérez-Donsión, "Special Issue 'Analysis for Power Quality Monitoring," Energies, vol. 13, no. 3, p. 514, 2020, doi: 10.3390/en13030514.

[13] K. T. Chui, M. D. Lytras, and A. Visvizi, "Energy sustainability in smart cities: Artificial intelligence, smart monitoring, and optimization of energy consumption," Energies, vol. 11, no. 11, pp. 1-20, 2018, doi: 10.3390/en11112869.

[14] K. Matsui, "An information provision system to promote energy conservation and maintain indoor comfort in smart homes using sensed data by IoT sensors," Futur. Gener. Comput. Syst., vol. 82, pp. 388-394, 2018, doi: 10.1016/j.future.2017.10.043.

[15] S. Porru, F. E. Misso, F. E. Pani, and C. Repetto, "Smart mobility and public transport: Opportunities and challenges in rural and urban areas," J. Traffic Transp. Eng. (English Ed., vol. 7, no. 1, pp. 88-97, 2020, doi: 10.1016/j.jtte.2019.10.002.

[16] S. Liyanage, H. Dia, R. Abduljabbar, and S. A. Bagloee, "Flexible mobility on-demand: An environmental scan," Sustain., vol. 11, no. 5, 2019, doi: 10.3390/su11051262.

[17] F. Behrendt, "Why cycling matters for Smart Cities. Internet of Bicycles for Intelligent Transport," J. Transp. Geogr., vol. 56, pp. 157-164, 2016, doi: 10.1016/j.jtrangeo.2016.08.018.

[18] F. Behrendt, "Cycling the smart and sustainable city: Analyzing EC policy documents on internet of things, mobility and transport, and smart cities," Sustain., vol. 11, no. 3, 2019, doi: 10.3390/su11030763.

[19] S. Poslad, A. Ma, Z. Wang, and H. Mei, "Using a smart city IOT to incentivise and target shifts in mobility behaviour-Is it a piece of pie?," Sensors (Switzerland), vol. 15, no. 6, pp. 13069-13096, 2015, doi: 10.3390/s150613069.

[20] S. E. Bibri, "The IoT for smart sustainable cities of the future: An analytical framework for sensor-based big data applications for environmental sustainability," Sustain. Cities Soc., vol. 38, no. October 2017, pp. 230-253, 2018, doi: 10.1016/j.scs.2017.12.034.

[21] P. Bellavista, C. Giannelli, and R. Zamagna, "The PeRvasive environment sensing and sharing solution," Sustain., vol. 9, no. 4, pp. 1-17, 2017, doi: 10.3390/su9040585.

[22] B. Mataloto, J. C. Ferreira, and N. Cruz, "Lobems-IoT for building and energy management systems," Electron., vol. 8, no. 7, 2019, doi: 10.3390/electronics8070763.

[23] D. Sembroiz, D. Careglio, S. Ricciardi, and U. Fiore, "Planning and operational energy optimization solutions for smart buildings," Inf. Sci. (Ny)., vol. 476, pp. 439-452, 2019, doi: 10.1016/j.ins.2018.06.003. energy management platform for public buildings," Electron., vol. 7, no. 11, pp. 1-13, 2018, doi: 10.3390/electronics7110294.

[25] J. Han, E. Lee, H. Cho, Y. Yoon, H. Lee, and W. Rhee, "Improving the energy saving process with high-resolution data: A case study in a university building," Sensors (Switzerland), vol. 18, no. 5, 2018, doi: $10.3390 / \mathrm{s} 18051606$.

[26] J. Pan, R. Jain, S. Paul, T. Vu, A. Saifullah, and M. Sha, "An Internet of Things Framework for Smart Energy in Buildings: Designs, Prototype, and Experiments," IEEE Internet Things J., vol. 2, no. 6, pp. 527-537, 2015, doi: 10.1109/JIOT.2015.2413397.

[27] S. Yadav, D. Garg, and S. Luthra, "Selection of third-party logistics services for internet of things-based agriculture supply chain management," Int. J. Logist. Syst. Manag., vol. 35, no. 2, p. 204, 2020, doi: 10.1504/ijlsm.2020.104780.

[28] K. A. Brohm, "Key drivers of the implementation of smart technology in the food value chain: Innovation for a sustainable food production," Int. J. Innov. Technol. Explor. Eng., vol. 8, no. 8, pp. 462-465, 2019.

[29] A. Telukdarie and P. Dhamija, "The IoT research in sustainable agricultural supply chain management: A conceptual framework," Int. J. E-entrepreneursh. Innov., vol. 9, no. 2, pp. 1-14, 2019, doi: 10.4018/IJEEI.2019070101

[30] R. Accorsi, S. Cholette, R. Manzini, and A. Tufano, "A hierarchical data architecture for sustainable food supply chain management and planning," J. Clean. Prod., vol. 203, pp. 1039-1054, 2018, doi: 10.1016/j.jclepro.2018.08.275

[31] C. N. Verdouw, R. M. Robbemond, T. Verwaart, J. Wolfert, and A. J. M. Beulens, "A reference architecture for IoT-based logistic information systems in agri-food supply chains," Enterp. Inf. Syst., vol. 12, no. 7, pp. 755-779, 2018, doi: 10.1080/17517575.2015.1072643.

[32] M. Muñoz, J. D. Gil, L. Roca, F. Rodríguez, and M. Berenguel, “An iot architecture for water resource management in agroindustrial environments: A case study in almería (Spain)," Sensors (Switzerland), vol. 20, no. 3, 2020, doi: 10.3390/s20030596.

[33] C. Kamienski et al., "Smart water management platform: IoT-based precision irrigation for agriculture," Sensors (Switzerland), vol. 19, no. 2, 2019, doi: 10.3390/s19020276.

[34] G. Bressanelli, F. Adrodegari, M. Perona, and N. Saccani, "Exploring how usage-focused business models enable circular economy through digital technologies," Sustain., vol. 10, no. 3, 2018, doi: 10.3390/su10030639.

[35] F. E. Garcia-Muiña et al., "Identifying the equilibrium point between sustainability goals and circular economy practices in an Industry 4.0 manufacturing context using eco-design," Soc. Sci., vol. 8, no. 8 , 2019, doi: 10.3390/socsci8080241.

[36] F. E. Garcia-Muiña, R. González-Sánchez, A. M. Ferrari, and D. Settembre-Blundo, "The paradigms of Industry 4.0 and circular economy as enabling drivers for the competitiveness of businesses and territories: The case of an Italian ceramic tiles manufacturing company," Soc. Sci., vol. 7, no. 12, 2018, doi: 10.3390/socsci7120255

[37] G. Hatzivasilis, K. Fysarakis, O. Soultatos, I. Askoxylakis, I. Papaefstathiou, and G. Demetriou, "The Industrial Internet of Things as an enabler for a Circular Economy Hy-LP: A novel IIoT 
protocol, evaluated on a wind park's SDN/NFV-enabled 5G industrial network," Comput. Commun., vol. 119, no. September 2017, pp. 127-137, 2018, doi: 10.1016/j.comcom.2018.02.007.

[38] M. A. Reuter, "Digitalizing the Circular Economy: Circular Economy Engineering Defined by the Metallurgical Internet of Things," Metall. Mater. Trans. B Process Metall. Mater. Process. Sci., vol. 47, no. 6, pp. 3194-3220, 2016, doi: 10.1007/s11663-0160735-5.

[39] K. D. Kang, H. Kang, I. M. S. K. Ilankoon, and C. Y. Chong, "Electronic waste collection systems using Internet of Things (IoT): Household electronic waste management in Malaysia," J. Clean. Prod., vol. 252, p. 119801, 2020, doi: 10.1016/j.jclepro.2019.119801.

[40] P. Jiang, Y. Van Fan, J. Zhou, M. Zheng, X. Liu, and J. J. Klemeš, "Data-driven analytical framework for waste-dumping behaviour analysis to facilitate policy regulations," Waste Manag., vol. 103, pp. 285-295, 2020, doi: 10.1016/j.wasman.2019.12.041. 